Title

Effects of simulated crouch gait on foot kinematics and kinetics in healthy children

\title{
Authors
}

\section{Julia Balzer}

Department of Physiotherapy

University Zurich Children's Hospital

Rehabilitation Centre

Mühlebergstrasse 104

$\mathrm{CH}-8910$ Affoltern am Albis

Switzerland

Tel: +4144762 5279

Email: Julia.Balzer@kispi.uzh.ch

\section{Sarah Schelldorfer,}

Christoph Bauer

Department of Physiotherapy

Zurich University of applied Science (ZHAW)

Technikumstrasse 71

$\mathrm{CH}-8401$ Winterthur

Tel: +41589346449

Email: Sarah.schelldorfer@zhaw.ch, Christoph.bauer@zhaw.ch

Dr. Marietta $L$ van der Linden

Rehabilitation Sciences

School of Health Sciences

Queen Margaret University

Edinburgh, EH21 6UU

Tel: +441314740000

Email: MVanDerLinden@qmu.ac.uk

Each of the authors has read and concurs with the content of the final manuscript. The material within has not been and will not be submitted for publication elsewhere except as an abstract.

Acknowledgements The authors would like to thank the team of the human movement laboratory of the "Zurich University of applied Science" (ZHAW)" in Winterthur (Switzerland) for providing the equipment and technical support required to conduct this study.

Keywords $\quad$ Crouch gait; Foot; Compensation; Gait analysis; Cerebral Palsy 


\begin{abstract}
Identification of secondary and tertiary impairments in neurologically induced gait deviations, such as crouch gait, is not always straightforward, but essential in order to decide upon the most efficient medical treatment in patients with cerebral palsy (CP). Until now, exact intersegmental dependency of the development of foot deformities has not been investigated. Therefore, the aim of this study was to explore if an artificially induced bilateral knee flexion contracture causes compensatory mechanisms in foot motion during gait in healthy children.
\end{abstract}

Three-dimensional kinematic and kinetic data from 30 healthy children (mean age 10.6 years) were derived from the Oxford Foot model (OFM). Participants walked first in an artificially induced crouch gait (limitation of knee extension to $40^{\circ}$ ) and then normally. Walking speed was kept the same in both conditions.

Analysis revealed small but significant $(p<0.05)$ differences between the two conditions in hindfoot and forefoot kinematics in all three planes during the stance phase as well as for all peak internal moments within the foot. In general the foot tended to compensate for an artificial knee flexion contracture with an increase in maximal dorsiflexion, eversion and external rotation of the hindfoot, which also allowed increased foot motion in other foot segments.

The results of this study showed that an isolated proximal joint contracture had an influence on foot position during stance in healthy children. Further interpretation of the data in relation to $\mathrm{CP}$ children will be possible as soon as comparable OFM data of pathological crouch gait is available. 


\section{Introduction}

The nature of neurologically induced gait pathologies, like in children with cerebral palsy (CP), is complex [1]. During clinical assessment, clear allocation of cause and effect mechanisms between primary, secondary and tertiary gait impairments is difficult due to neurological and intersegmental dependencies, but essential in deciding upon the most efficient medical treatment [2]. This is especially important for progressive gait deviations like crouch gait, which is characterized by excessive knee flexion $\left(\geq 20^{\circ}\right)$ and increased hip flexion during stance phase of the gait $[3,4,5]$. Known risk factors for the progression of crouch gait are increased knee flexion as well as the change in foot deformity. During an early state of crouch gait an apparent equinus is often present, which later on progresses or changes into an equinoplanovalgus deformity $[2,3,5]$. In order to be able to delay this progression and thereby to preserve the child's walking ability, it is crucial to gain a better understanding of the development of these risk factors. Traditionally weak and short calf- and intrinsic foot-muscles as well as malrotated lever arms are thought to be causative for the development of an equinoplanovalgus deformity [2].

Although three dimensional gait analysis (3DGA) enabled more accurate measurement and thereby increased the biomechanical understanding of this gait deviation $[6,7]$, the development of foot deformities are still not exactly understood. This lack of knowledge is on the one hand related to the previously limited interpretation of $3 \mathrm{D}$ foot data in relation to the conventionally used single vector model of the foot [8] and on the other hand due to the limited number of studies conducted with respect to this topic.

Most of the studies on foot deformities in children with CP focused on local and more proximal effects of isolated surgical correction of equinus foot deformity [9-12]. The results of these studies showed that, although after correcting an equinus deformity ankle kinematics were significantly improved, the surgical correction had a smaller and more variable effect on more proximal joints like the knee. Studies which investigated the correction of more severe crouch gait deformities, like a knee flexion contracture $[13,14]$ or a pes equinopalnovalgus 
deformity [17-19], were either multilevel surgeries, not allowing to clearly allocate the effect of correcting one isolated joint deformity, or had chosen for local outcome measures and did not investigate the surgical effect on other joints.

Another problem in this patient population is that the primary underlying neurological impairments hamper a straightforward allocation of secondary impairments (i.e. knee flexion contracture) and the development of tertiary deformity. Consequently, measuring the effect of artificially induced contractures on healthy subjects, hence with no neurological interference, has been shown to be a meaningful approach. The studies from Matjačjæ and Olenšek [18], Van der Korgt et al. [19] and Whitehead et al. [20] used this approach to determine the effect of an artificially induced hamstrings and iliopsoas contracture on the nature of crouch gait in healthy adults. Their results showed that a short psoas muscle alone significantly increases flexion around the ankle, knee and hip. Thereby they disproved the traditional belief that a hamstring's contracture primarily causes a crouched walking pattern.

Therefore, the purpose of this study was to test the effect of an isolated bilateral knee flexion contracture on foot motion in healthy children using a recently developed multi-segment foot model. As healthy children, in contrast to CP children, are expected to have strong calf and foot muscles and a good overall motor control allowing them to adapt to the induced knee flexion, it was hypothesised that hindfoot and forefoot motion as well as ankle kinetics would not significantly differ between crouch and normal walking.

To the authors' knowledge this is the first study which investigated the effect of proximal joint abnormality on the foot by means of a multi-segment foot model [21]. 


\section{Method}

\section{Participants}

In the local area around the University Motion Analysis Laboratory 30 healthy children between 7.0 and 14.4 years were recruited by convenience sampling (Table 1). All participants had a medical history without any neurological and orthopaedic pathology of the lower limbs, a normal body mass index (BMI: $18.5-24.9 \mathrm{~kg} / \mathrm{m}^{2}$ ) and had a shoe size larger than 32EUR. Written informed consent and assent was obtained from all subjects and their parents/guardians. The study was approved by the University research ethics committee.

\section{Measurement procedure}

Data collection took place at the University Motion Analysis Laboratory. All measurements were carried out by the first author and a trained assistant according to a standardized protocol. Bilateral kinematic data of the lower body were recorded by using a 7-camera Vicon MX motion capture system and Vicon Nexus 1.4 software (Oxford Metrics Group, Oxford, UK). Marker (9.5 mm diameter) movement and kinetic data from two force plates (AMTI, Boston, MA, USA) were collected at $200 \mathrm{~Hz}$ and $1000 \mathrm{~Hz}$ respectively.

Marker placement for the Oxford Foot Model (OFM) was carried out in accordance with the protocol of Stebbins et al. [22]. Correct marker and knee alignment device placement (during the static trial) were checked by capturing and processing two dynamic normal walking trials of each participant prior to data collection. When correct placement was assured, a specially designed hip-knee-belt was applied to the participant's lower body in order to produce a symmetric artificial knee flexion contracture of $40^{\circ}$ (Fig. 1). Placement of the hip-knee-belt was carried out in accordance to brace placement in the study by Whitehead et al. (2007). The belts were made of a non-slippery soft bandage material (FABRIOFOAM ${ }^{\mathrm{TM}}$, Tensowrap $\mathrm{Nu}$ ) and the straps between the hip and knee belt were made of non-stretch nylon webbing. Bilateral sagittal knee alignment of $40^{\circ}$ flexion was assured in standing position by using a hand-held goniometer and by tightening the straps accordingly. Knee extension was limited 
to this angle as an extension deficit of $40^{\circ}$ during midstance is often seen after the transition from mild to more severe crouch gait [2]. After giving the participant three minutes to accustom him/herself to walk in this flexed walking pattern, dynamic data collection started. Participants were instructed to look straight ahead and to walk to the other end of the gait laboratory. Four trials of both the right and the left leg, (if the right/left foot only landed on either of the two force places) during walking were recorded. Next the knee-belt was removed and the child was asked to walk normally within the same speed range as during crouch, in order to avoid any speed induced kinematic differences between the two conditions [23]. Walking speed was controlled first by measuring the numbers of frames the child needed to walk through the previously defined calibration space. In addition the child was verbally instructed to match the walking speed during the crouch session. Data collection of normal walking was stopped when four successful trials of each leg had been captured.

\section{Data analysis}

The three kinematic and kinetic most consistent trials for each condition were selected by visual inspection for further analysis using Polygon 3.5.1 (Oxford Metrics Group, Oxford, UK). Peak values of the following maximum kinematic and kinetic outcome variables during stance phase were executed using Matlab R2010a (Mathworks, Natrick, USA): hindfoot and forefoot dorsiflexion, hindfoot inversion and internal rotation, forefoot supination and adduction as well as the internal plantarflexion-, valgus and internal rotation moment of the foot.

\section{Statistical analysis}

The Shapiro-Wilks test was used for assessing normality for the outcome variables described above. For those normally distributed, a paired t-test was used to analyse the mean difference between the two conditions while for those not normally disturbed the Wilcoxon test was used to analyse differences between medians. Differences with a $p$ value smaller 
than 0.05 were accepted as statistically significant, SPSS 17,0 (IBM, Armonk, USA) was used for all statistical analyses.

\section{Results}

Table 1 summarizes the participants' characteristics of the 30 data sets which were included in this study. Ten data sets were excluded due to minor gait deviations (i.e. tibia torsion $<10$ or $>20^{\circ}$ ) and / or missing variable values due to marker loss or other technical faults which became obvious during data processing.

Table 2 summarizes the most important descriptive parameters for each variable. Gait curves of all measurement outcomes are shown in Figure 2 and 3. Significant differences between normal and artificial crouched walking were found for all foot outcome variables analysed in this study (Table 2). Walking speed was similar in normal $(0.66 \mathrm{~m} / \mathrm{s})$ and crouch $(0.65 \mathrm{~m} / \mathrm{s})$ walking conditions. In the sagittal plane, maximal knee flexion during the stance phase, which was artificially increased by wearing the knee-brace during crouch, was on average $45^{\circ}$ greater in crouch than during normal gait.

On average, participants showed significantly more maximal sagittal hindfoot and forefoot motion during stance phase when walking in artificial crouch than when walking normally (hindfoot: Mean (M) maximal values: $M=19.2$ vs $M=7.1^{\circ}$; forefoot: $M=14.6^{\circ}$ vs $M=12.5^{\circ}$, $p<0.001)$.

In the frontal plane the hindfoot was everted during stance while walking in crouch and inverted when walking normally (Mean maximal values: $M=-1.0^{\circ}$ vs $M=2.8^{\circ}, p<0.001$ ). The forefoot was less supinated during artificial crouch compared to normal walking (Mean maximal values: $M=5.9^{\circ}$ vs $M=7.4^{\circ}$ ).

In the transverse plane the hindfoot was externally rotated when walking in crouch, while in the normal condition the hindfoot was internally rotated (Mean maximum values: $M=-4.6^{\circ}$ 
vs $\left.M=5.9^{\circ}, p<0.001\right)$. Further, the forefoot was significantly more adducted during artificial crouch gait than during normal gait (Median (Mdn) maximum values: $\mathrm{Mdn}=10.4^{\circ}$ vs $\mathrm{Mdn}=$ $\left.7.6^{\circ}, p<0.001\right)$

Kinetic data of the foot showed that the median maximal internal plantarflexion moment in stance was significantly reduced during artificial crouch gait than when walking normally $(\mathrm{Mdn}=1.16 \mathrm{Nm} / \mathrm{kg}$ versus $\mathrm{Mdn}=-1.09 \mathrm{Nm} / \mathrm{kg},(p<0.001)$.

Median maximal internal valgus and internal rotation moment were significantly greater during crouch than during normal walking (valgus moment: $\mathrm{Mdn}=0.2 \mathrm{Nm} / \mathrm{kg}$ vs $\mathrm{Mdn}=0.15$ $\mathrm{Nm} / \mathrm{kg}$; internal rotation moment: $\mathrm{Mdn}=1.14 \mathrm{Nm} / \mathrm{kg}$ vs $\mathrm{Mdn}=0.11 \mathrm{Nm} / \mathrm{kg}, \mathrm{p}<0.05)$. 


\section{Discussion}

Motion of the hindfoot relative to the tibia and forefoot relative to the hindfoot in all three planes of motion, as well as the moments within the foot segments were found to be significantly different between the artificially induced crouch and normal gait. The comparison of walking speeds showed these differences were not due to a difference in walking speed, as walking speed between the two conditions was successfully controlled and did not significantly differ between the two conditions. Although differences between the two conditions in kinematic and kinetic variables were small, they were statistically significant and showed consistent movement patterns (Fig 2 and 3). On average, participants compensated for the induced knee flexion with pronating (dorsiflexion, eversion and external rotation) of the hindfoot, a calcaneus position which is often seen in pathological crouch gait [2]. The increase in forefoot dorsiflexion might be caused by the eversion of the hindfoot, which effectively unlocks the midfoot. The less supinated and more adducted forefoot position in the induced crouch condition showed that the foot did not totally loose its stability. Artificial crouch resulted in a reduced peak plantar flexion moment compared to normal gait. This reduction might be due to the crouched position itself, as well as due to the unlocked midfoot, which makes the foot instable and unable to act as a stable lever arm for propulsion [2].

In general, due to the artificial knee flexion contracture, forward incline of the tibia over the stationary foot is greater during midstance in artificial crouch, thereby increasing dorsiflexion of the hindfoot. Furthermore, excessive knee flexion allowed for an increased motion between the multiple foot segments. This increase in motion between the three foot segments and especially the pronated hindfoot position during stance phase are known to

interfere with the normal stabilizing foot mechanics of this phase. Although the forefoot kinematics of the participants in this study showed that they were still able to stabilize the foot, it is questionable if this supposable muscular stabilization would be equally effective in neurological impaired patients. 
Therefore, an artificial knee flexion contracture can diminish the deceleration and stability function of the second ankle rocker as well as that it compromises the accelerating ability of the third rocker. As these changes in foot kinematics and kinetics were observed after only 15 min walking in artificial crouch gait, alternation in foot mechanics after a longer period of time might even have further consequences even in healthy participants. In case of a CP child with a knee flexion contracture, who is forced to walk in this bend position for a longer time and whose muscles strength and control are known to be diminished [2], development of a midfoot break and an equinoplanovalgus deformity in relation to such a contracture, are conceivable. Consequently any mechanical or therapeutic treatment aiming to improve knee extension in $\mathrm{CP}$ children may also reduce one possible risk factor for compensation mechanisms around the foot. However, any meaningful interpretation regarding possible mechanisms in children with CP should be made with caution, as there are no studies offering comparable 3D foot data from the CP crouch population as derived by the OFM. Clinical diagnosis of foot deformities is mainly based on weight bearing radiographic assessment techniques, visual gait analysis and plantar pressure measurement techniques. Until now, only a small number of studies has investigated in vivo motion hindfoot $[24,25]$ and forefoot motion $[21,26,27]$ during gait in healthy adults. Verification of clinical diagnosis of foot deformities in the paediatric population during gait with a multi-segment foot model like the OFM is still needed [28].

The data from this study would be very appropriate for a meaningful comparison with OFM data from CP children with crouch gait, since walking speed and the degree of knee flexion in this study are similar to those with CP [23]. Nevertheless the findings of this study have to be regarded with caution, as crouch gait in our study was solely induced by an increased sagittal knee angle. In the population of interest, crouch gait might be also induced by other factors such as an instable foot, weak extensor muscles and poor selective control of the lower limb [2]. All these impairments reduce the ability to adequately control the knee joint during stand phase and thereby force the child into a crouch position. Besides these 
differences in onset between pathological and artificial crouch gait, CP children who primarily walk in crouch gait due to a knee flexion contracture may not be able to compensate in the same way as the participants of this study. All participants in this study had strong and intact plantar- and dorsiflexors and could thereby counterforce the increased loading of the plantar, medial portion of the midfoot during crouch. Furthermore, their kinematic curves showed normal patterns, even though kinematic values were altered, indicating that their physiological gait pattern is still present. Children with $\mathrm{CP}$ have never experienced a physiological gait pattern, and might therefore not able maintain their control as good as healthy children, especially not around such a distal segment as the foot.

In relation to the measurement procedure, practical difficulties in correct marker placement of the hindfoot segment were experienced. The small calcaneus surface of a child made fixation of the CEPG as well as exact placement of the two other markers difficult. During walking skin movement and furthermore detachment of the CEPG were recognized. These problems might be related to the high inter-subject variance for the hindfoot-tibia motion mainly in the frontal plane, which was found in this study, and which has also been reported by previous studies $[28,29]$. 


\section{Conclusion}

In conclusion, the results of this study showed that a single knee flexion contracture has an influence on foot motion during gait in healthy children. Applied to CP children with crouch gait, this means that a knee flexion contracture is one of the possible risk factors which is causative for developing a foot deformity. In order to verify these findings, further studies recording OFM data of CP children walking with crouch gait need to be conducted.

Conflict of interest statement: None of the authors are aware of any financial or personal relationships with other people or organizations that could improperly influence this work.

Funding: This piece of research was conducted as a part of the postgraduate master degree in physiotherapy of the first author and was financed by the student herself.

Total words: 2997 


\section{References}

[1] Kirtley C. Clinical Gait Analysis - Theory and Practice. Philadeplhia: Elsvier; 2006.

[2] Gage JR, Schwartz MH, Koop SE, Novacheck TF. The identification and treatment of gait problems in cerebral palsy. 2nd ed. London: Mac Keith Press; 2009.

[3] Sutherland D. The development of mature gait. Gait Posture 1997; 6: 163-70.

[4] Rodda J, Graham HK. Classification of gait patterns in spastic hemiplegia and spastic diplegia:a basis for a management algorithm. EurJ Neurol 2001; 8:98-108.

[5] Wren TA, Rethlefsen S, Kay RM. Prevalence of specific gait abnormalities in children with cerebral palsy: influence of cerebral palsy subtype, age, and previous surgery. J Pediatr Orthop 2005; 25:79-83.

[6] Sutherland D. The evolution of clinical gait analysis. Gait Posture 2002; 16:159-79.

[7] Curran SA, Dananberg H. Future of Gait Analysis: A Podiatric Medical Perspective. J Am Podiat Med Assoc 2005; 95: 133-45.

[8] Baker R, Robb J. Foot models for clinical gait analysis. Gait Posture 2006; 23: 339-400.

[9] Baddar A, Granata K, Damiano DL, Carmines D L, Blanco JS, Abel MF. Ankle and Knee Coupling in Patients with Spastic Diplegia: Effect of Gastrocnemius-Soleus Lengthening. J Bone Joint Surg 2002; 84: 736-44. 
[10] Tylkowski CM, Horan M, Donna JO. Outcomes of Gastrocnemius-soleus Complex Lengtehning for Isolated Equinus Contracture in Children with Cerebral Palsy. J Pediatr Orthop 2009; 29: 771-78.

[11] Lofterød B, Terjesen' T. Local and distant effects of isolated calf muscle lengthening in children with cerebral palsy and equinus gait. J Child Orthop 2008; 2: 55-61.

[12] Stebbins J, Harrington M, Thompson N, Zavatsky A, Theologis T.Gait compensations caused by foot deformity in cerebral palsy. Gait Posture 2010; 32: 226-30.

[13] Stout JL, Gage JR, Schwartz MH.Distal femoral extension osteotomy and patellar tendon advancement to treat persistent crouch gait in cerebral palsy. J Bone Joint Surg Am 2008; 90: 2470-84.

[14] Rodda JM, Graham HK, Nattrass GR, Galea MP, Baker R, Wolfe R. Correction of Severe Crouch Gait in Patients with Spastic Diplegia with Use of Multilevel Orthopaedic Surgery. J Bone Joint Surg Am 2006; 88: 2653-64.

[15] Noritake K, Yoshihashi Y, Miyata T. Calcaneal lengthening for planovalgus foot deformity in children with spastic cerebral palsy. J Pediatr Orthop 2005 ;14: 274-279.

[16] Muir D, Richard A, Gary N, Graham H. Tibiotalocalcaneal Arthrodesis for Severe Calcaneovalgus Deformity in Cerebral Palsy. J Pediatr Orthop 2005; 25: 651-656. 
[17] Roger L, Xuechen L, Schwab J, Harris G. Kinematic and Kinetic Evaluation of the Ankle Joint Before and After Tendo Achilles Lengthening in Patients with Spastic Diplegia. J Pediatr Orthop 2005.; 25: 479-83.

[18] Matjačjæ Z., Olenšek A. Biomechanical characterization and clinical implications of artificially induced crouch walking: Differences between pure iliopsoas, pure hamstrings and combination of liopsoas and hamstrings contractures. Journal of Biomechanics 2007,40: 491-501.

[19] Van der Krogt MM, Doorenbach CAM, Harlaar J. Muscle length and lengthening velocity in voluntary crouch gait. Gait Posture 2007; 26: 523-38.

[20] Whitehead CL, Hillman SJ, Richardson AM, Hazelwood ME. The effect of simulated hamstring shortening on gait in normal subjects. Gait Posture 2007; 26: 90-96.

[21] Carson MC, Harrington ME, Thompson N, O Connor JJ, Theologis TN. Kinematic analysis of a muti-segment foot model for research and clinical application, a repeatability analysis. J Biomech 2001; 34:1299-307.

[22] Stebbins J, Harrington M, Thompson N, Zavatsky A, Theologis T. Repeatability of a model for measuring multi-segment foot kinematics in children. Gait Posture 2006; 23: 401-10.

[23] Van der Linden ML, Kerr AM, Hazelwood ME, Hillman SJ, Robb KE. Kinematic and Kinetic Gait Characteristic of Normal Children Walking at a Range of Clinically Relevant Speeds. J Pediatr Orthop 2002; 22: 800-06. 
[24] Liu W, Sieger S, Hillstrom H, Whitney K. Three-dimensional, six-degrees-of-freedom kinematics of the human hindfoot during the stance phase of level walking. Hum Mov Sci 1997; 16: 283-98.

[25] Reinschmidt C, van den Bogert AJ, Lundberg A; Nigg BM; Murphy N; Stacoff A, Stano A. Tibiofemoral and tibiocalcaneal motion during walking: external vs. skeletal markers. Gait Posture 1997; 6: 98-109.

[26] Leardini A, Benedetti MG, Catani F, Simoncini L, Giannini S. An anatomically based protocol for the description of foot segment kinematics during gait. Clin Biomech(Bristol, Avon)1999; 14: 528-36.

[27] MacWilliams BA, Cowely M, Nicholson DE. Foot kinematics and kinetics during adolescent gait. Gait Posture 2003; 17: 214-24.

[28] Curtis DJ, Bencke J, Stebbins JA, Stansfield B. Intra-rater repeatability of the Oxford foot model in healthy children in different stages of the foot roll over process during gait. Gait Posture 2009; 30: 118-21.

[29] Wright CJ, Brent LA, Coffey TG, Pidcoe PE. Repeatability of the modified Oxford foot model during gait in healthy adults. Gait Posture 2011; 33: 108-12. 
Table 1: Mean and standard deviations of participants' characteristics

\begin{tabular}{ll}
\hline Gender & 15 male / 15 female \\
\hline Age (years) & $10.6 \pm 1.8$ \\
\hline Body Mass $\mathbf{( k g )}$ & $34.6 \pm 9.0$ \\
\hline Height $(\mathbf{m})$ & $1.44 \pm 0.1$ \\
\hline Body Mass $\mathbf{l n d e x} \quad \mathbf{( k g / \mathbf { m } ^ { 2 } )}$ & $34 \pm 4$ \\
\hline Shoe Size $\mathbf{( m m )}$ & $233 \pm 13$ \\
\hline
\end{tabular}

Values represent mean \pm SD. 
Table 2: Summary Results: maximal kinematic and kinetic outcome values during stance phase of the gait cycle

\begin{tabular}{|c|c|c|c|c|}
\hline $\begin{array}{l}\text { Mean maximal variable } \\
\text { during stance }\end{array}$ & Mean (SD) & Median & $\begin{array}{c}\text { Range } \\
\text { (min-max) }\end{array}$ & p-Value: \\
\hline $\begin{array}{l}\text { Knee Flex } \\
\text { Normal (deg) } \\
\text { Crouch(deg) }\end{array}$ & $\begin{array}{l}14(3.8) \\
59(6.6)\end{array}$ & $\begin{array}{c}14 \\
60.53\end{array}$ & $\begin{array}{c}9.4-23.5 \\
47.4-71.4\end{array}$ & $0.001^{*}$ \\
\hline $\begin{array}{l}\text { Hindfoot-Dorsiflexion } \\
\text { Normal (deg) } \\
\text { Crouch (deg) }\end{array}$ & $\begin{array}{c}7.1(2.9) \\
19.2(4.2)\end{array}$ & $\begin{array}{c}7.1 \\
20.0\end{array}$ & $\begin{array}{c}1.6-13.3 \\
10.3-25.7\end{array}$ & $0.001^{*}$ \\
\hline $\begin{array}{l}\text { Hindfoot Inversion } \\
\text { Normal (deg) } \\
\text { Crouch (deg) }\end{array}$ & $\begin{array}{l}2.8(4.4) \\
-1.0(3.8)\end{array}$ & $\begin{array}{l}3.1 \\
-1.1\end{array}$ & $\begin{array}{l}-7.5-12.4 \\
-13.2-7.6\end{array}$ & $0.001^{*}$ \\
\hline $\begin{array}{l}\text { Hindfoot Intern. Rotation } \\
\text { Normal (deg) } \\
\text { Crouch (deg) }\end{array}$ & $\begin{array}{l}5.9(3.4) \\
-4.6(3.7)\end{array}$ & $\begin{array}{l}6.6 \\
-4.6\end{array}$ & $\begin{array}{l}-0.9-13.8 \\
-11.0-2.8\end{array}$ & $0.001^{*}$ \\
\hline $\begin{array}{l}\text { Forefoot Dorsiflexion } \\
\text { Normal (deg) } \\
\text { Crouch(deg) }\end{array}$ & $\begin{array}{l}12.5(3.5) \\
14.6(3.7)\end{array}$ & $\begin{array}{l}12.6 \\
15.2\end{array}$ & $\begin{array}{l}5.6-19.8 \\
6.6-21.5\end{array}$ & $0.001^{*}$ \\
\hline $\begin{array}{l}\text { Forefoot Supination } \\
\text { Normal (deg) } \\
\text { Crouch(deg) }\end{array}$ & $\begin{array}{l}7.4(4.9) \\
5.9(5.3)\end{array}$ & $\begin{array}{l}6.4 \\
5.7\end{array}$ & $\begin{array}{c}0.9-17.6 \\
-4.1-18.3\end{array}$ & $0.004^{*}$ \\
\hline $\begin{array}{l}\text { Forefoot Adduction } \\
\text { Normal (deg) } \\
\text { Crouch (deg) }\end{array}$ & $\begin{array}{c}8.6(4.1) \\
10.7(3.2)\end{array}$ & $\begin{array}{c}7.6 \\
10.4\end{array}$ & $\begin{array}{l}1.6-15.2 \\
4.7-16.6\end{array}$ & $0.001^{* *}$ \\
\hline $\begin{array}{l}\text { Plantarflex. moment } \\
\text { Normal }(\mathrm{Nm} / \mathrm{kg}) \\
\text { Crouch }(\mathrm{Nm} / \mathrm{kg})\end{array}$ & $\begin{array}{l}1.20(0.15) \\
1.10(0.13)\end{array}$ & $\begin{array}{l}1.16 \\
1.09\end{array}$ & $\begin{array}{l}1.01-1.57 \\
0.71-1.43\end{array}$ & $0.001^{* *}$ \\
\hline $\begin{array}{l}\text { Valgus moment } \\
\text { Normal }(\mathrm{Nm} / \mathrm{kg}) \\
\text { Crouch }(\mathrm{Nm} / \mathrm{kg})\end{array}$ & $\begin{array}{c}0.15(0.06) \\
0.2(0.08)\end{array}$ & $\begin{array}{l}0.15 \\
0.20\end{array}$ & $\begin{array}{c}0.06-0.25 \\
0.04-3.6\end{array}$ & $0.002^{* *}$ \\
\hline $\begin{array}{l}\text { Intern. Rot moment } \\
\text { Normal }(\mathrm{Nm} / \mathrm{kg}) \\
\text { Crouch }(\mathrm{Nm} / \mathrm{kg})\end{array}$ & $\begin{array}{l}0.12(0.04) \\
0.16(0.06)\end{array}$ & $\begin{array}{l}0.11 \\
1.14\end{array}$ & $\begin{array}{l}0.05-0.58 \\
0.02-0.58\end{array}$ & $0.005^{* *}$ \\
\hline $\begin{array}{l}\text { Speed } \\
\text { Normal }(\mathrm{m} / \mathrm{s}) \\
\text { Crouch }(\mathrm{m} / \mathrm{s})\end{array}$ & $\begin{array}{l}0.66(0.11) \\
0.65(0.11)\end{array}$ & $\begin{array}{l}0.64 \\
0.65\end{array}$ & $\begin{array}{l}0.42-0.97 \\
0.40-0.88\end{array}$ & $0.672^{*}$ \\
\hline
\end{tabular}

Abbreviations: SD=standard deviation; $p$-value significant (2-tailed) at $p<0.05$, *=t-test, **Wilcoxon 


\section{Figures}

Fig. 1 Participant in artificially induced crouch gait

Fig. 2 Gait curves (100\% Gait cycle): mean hindfoot (first row) and forefoot (second row) movement in the sagittal, frontal and transversal plane (solid line: normal gait; dashed line: artificial crouch gait)

Fig. 3 Gait curves (100\% Gait cycle): mean internal ankle moment in the sagittal, frontal and transversal plane (solid line: normal gait; dashed line: artificial crouch gait) 


\section{Figure(s)}

Click here to download high resolution image

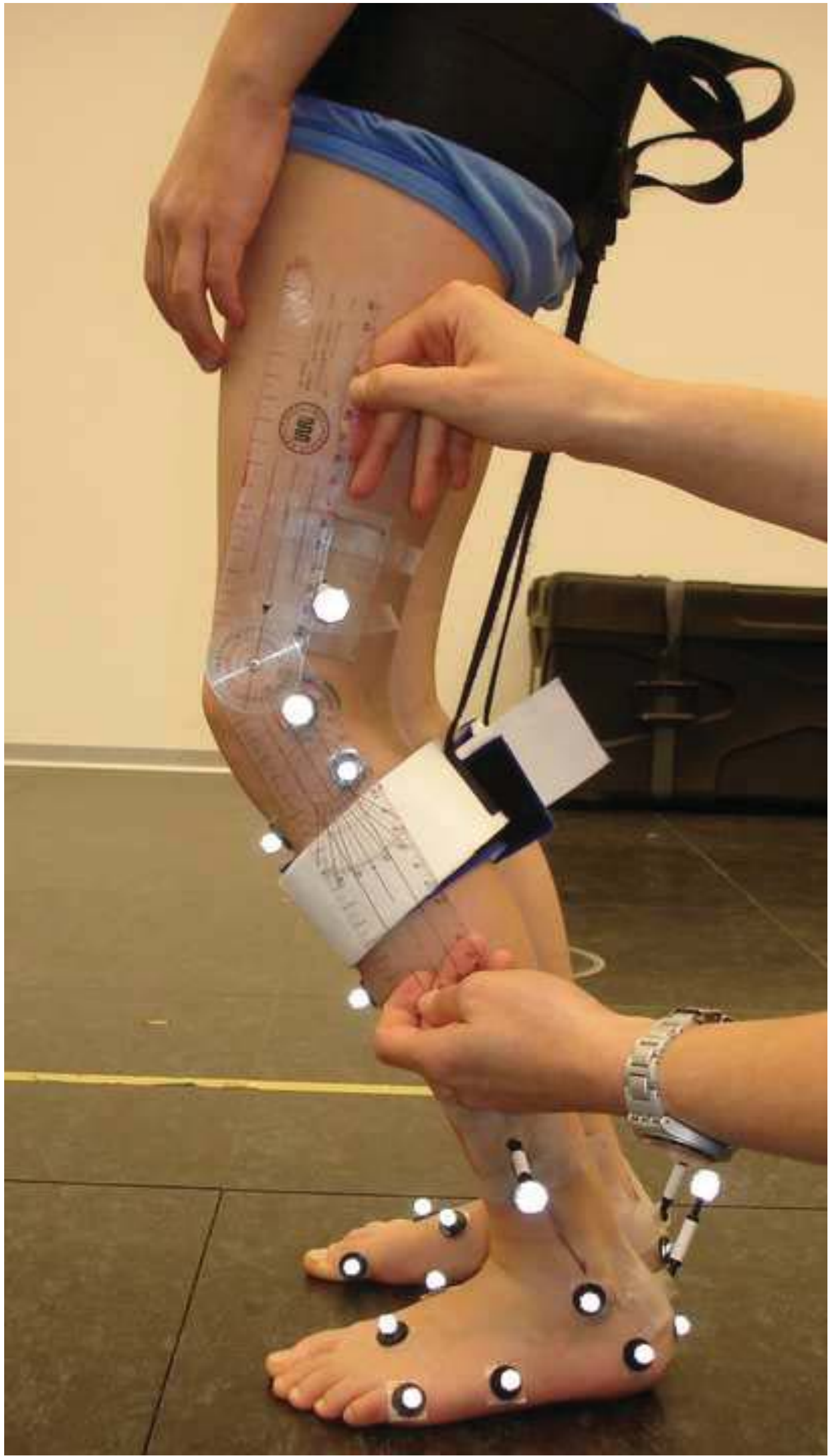




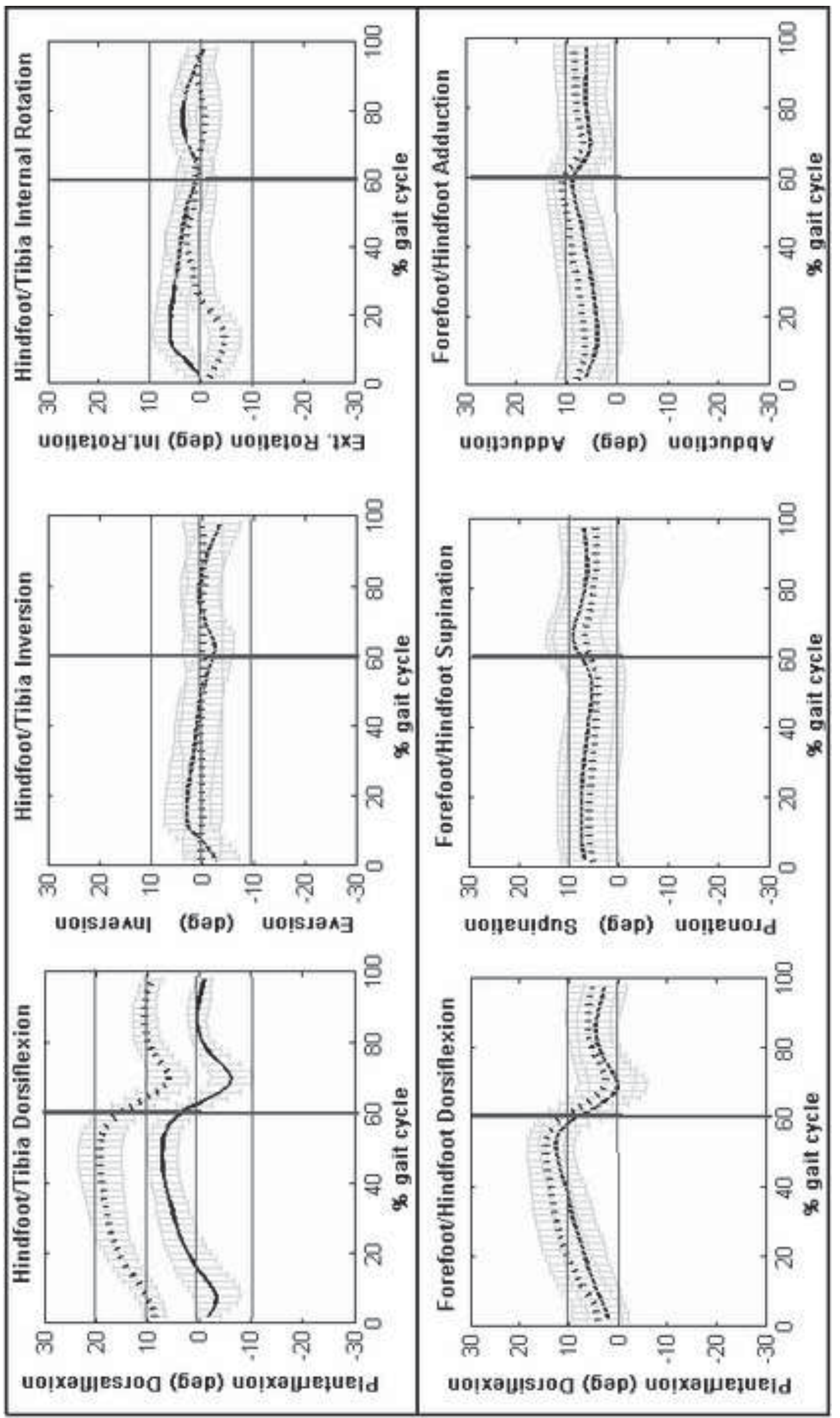




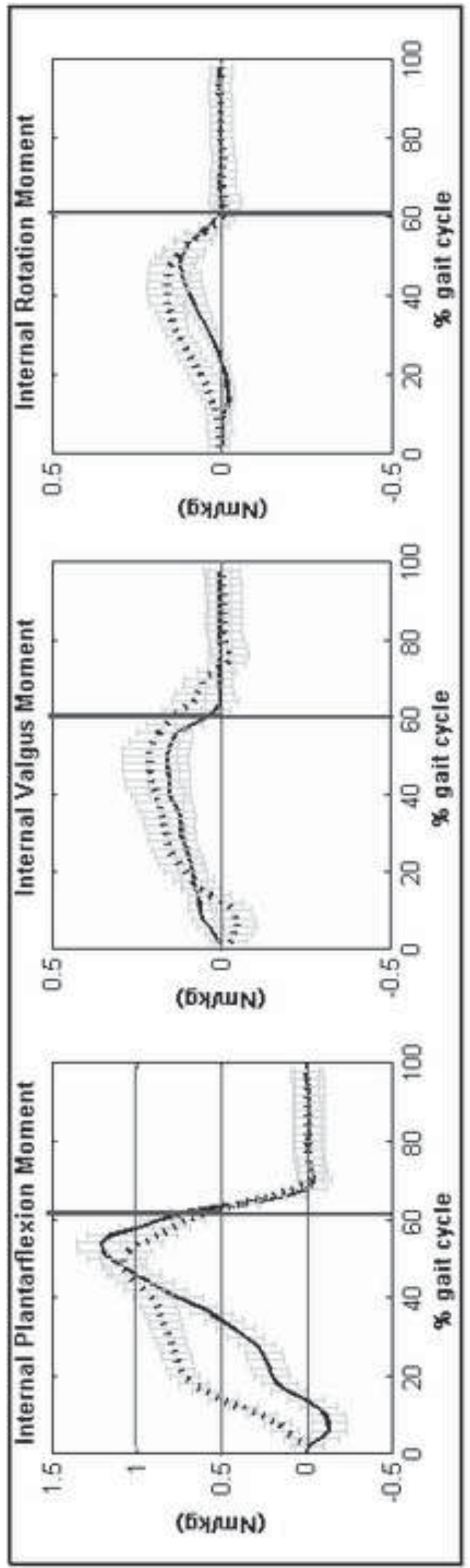


Research Highligts

- Significant differences between normal and artificial crouch gait during stance phase

- hindfoot compensation: dorsiflexion increased, eversion, external rotation

- forefoot compensation: dorsiflexion, adduction increased, supination decreased

- maximum plantarflexion moment decreased 